\title{
Was, wenn einer der Großväter der Verfassung beschnitten war?
}

verfassungsblog.de/wenn-einer-der-grovter-der-verfassung-beschnitten-war/

Mark Swatek-Evenstein Fr 31 Aug 2012

Fr 31 Aug

2012

Man könnte meinen, in der Debatte um das Beschneidungsurteil des Landgerichts Köln sei inzwischen so ziemlich alles gesagt. Aber in der viele Stimmen umfassenden Diskussion fehlt immer noch eine Einordnung der Entscheidung in einen größeren historischen Zusammenhang und die Frage nach der Vereinbarkeit der Kölner Entscheidung mit § 1 StGB und Art. 103 II GG. Beides kann hier nur, um mal ein besonders treffendes Wort zu nehmen, angeschnitten werden.

Das Landgericht Köln argumentiert bekanntlich, dass eine Einwilligung der Eltern in die Beschneidung nicht dem Kindeswohl diene und daher nicht für eine Rechtfertigung des medizinisch nicht gebotenen Eingriffs wirksam werden könne: „Die Grundrechte der Eltern aus Artikel 4 I, 6 II GG werden ihrerseits durch das Grundrecht des Kindes auf körperliche Unversehrtheit und Selbstbestimmung gemäß Artikel 2 I und II Satz 1 GG begrenzt. Das Ergebnis folgt möglicherweise bereits aus Artikel 140 GG i.V.m. Artikel 136 I WRV, wonach die staatsbürgerlichen Rechte durch die Ausübung der Religionsfreiheit nicht beschränkt werden.“

Was damit unausgesprochen kundgetan wird, ist, dass nach deutschem Verfassungsrecht die Beschneidung aus religiösen Motiven schon immer strafbar war, es sich jedoch bloß niemand gefunden hat, der bereit gewesen wäre, dies auch offen auszusprechen. Hiergegen spricht aber ohne Zweifel die deutsche Erfahrung: Als das Grundgesetz beraten wurde und schließlich in Kraft trat, war es keinesfalls unbekannt, dass im Judentum die Beschneidung zu einem identitätsstiftenden Merkmal erhoben worden ist. Es spricht nichts dafür, dass mit dem Grundgesetz auch ein Verbot dieser Praxis verbunden sein sollte. Im Gegenteil, das Grundgesetz hat insofern die Bestimmungen der Weimarer Verfassung übernommen und steht damit für eine Kontinuität im Hinblick auf die Garantie die Religionsfreiheit, die nicht anders gelesen werden kann, als dass rituelle Beschneidungen von Jungen nach dem Willen des historischen Gesetzgebers insbesondere auch mit Art. 136 I, IV der Weimarer Reichsverfassung vereinbar sein sollten.

Zur Erinnerung: Als die Weimarer Reichsverfassung von 1919 in Kraft trat, gab es in Deutschland etwas mehr als eine halbe Million Juden. Die Verfassung wurde wesentlich gestaltet von Hugo Preuß, für den die Erfahrung, dass Juden per Gesetz erst zu gleichberechtigten Staatsbürgern wurden, noch zur eigenen Lebenswirklichkeit gehörte. Für inn war der erfolgreiche Kampf um die rechtliche Gleichstellung von Juden noch Gegenwart und er war - womöglich auch deswegen - ein entschiedener Gegner der Forderung nach Assimilation. In einer Rede im Jahre 1925 verurteilte er solche Forderungen als anti-semitisch, denn deutsche Juden seien keine minderen Deutschen als „irgendein anderer“. Was jüdische Deutsche aber von anderen Deutschen damals wie heute unterscheidet, ist die Befolgung der jüdischen (gottgegebenen) Bräuche und für Preuß, den „Vater“ der Weimarer Verfassung, war es offensichtliche keine Frage, dass beides miteinander vereinbar sein sollte. Demnach spricht historisch gesehen alles dafür, dass mit der Garantie der Religionsfreiheit jedenfalls ursprünglich auch das Recht der Eltern, ihre Kinder entsprechend der überlieferten Bräuche ihrer Religion behandeln zu dürfen - und sei es, dass damit eine Beschneidung des acht Tage alten männlichen Säuglings verbunden war -, garantiert wurde. Die hohe Bedeutung der Beschneidung für ihre jüdischen Landsleute konnte den Deutschen der Weimarer Republik nicht verborgen bleiben: Wer ein wenig sucht, findet auch heute noch reichlich Zeugnisse deutscher Juden des ausgehenden 19. Jahrhunderts, in denen die Bedeutung der Beschneidung als identitätsstiftendes und -bestätigendes Ritual betont wird, während gleichzeitig auch das Bemühen erkennbar ist, dieses Ritual entsprechend dem damaligen medizinischen Kenntnisstand zu gestalten. Selbst wenn man anerkennt, dass die Inkorporation der Artikel der Weimarer Reichsverfassung keine unveränderte Übernahme des Rechtszustands der Weimarer Zeit bedeutet, sondern diese nunmehr im Zusammengang mit den übrigen Verfassungsbestimmungen des Grundgesetzes zu sehen ist, so führt doch an der Feststellung kein Weg vorbei, dass die rituelle Beschneidung (jedenfalls in ihrer jüdischen Variante) ursprünglich zum deutschen „ordre public“ gehörte. 
Die Beschneidung ist auch nicht, wie das Landgericht in Offenlegung seines christlichen

Religionsverständnisses meint, im Widerstreit mit dem „Interesse des Kindes später selbst über seine

Religionszugehörigkeit entscheiden zu können“. Sowohl nach muslimischem wie auch nach jüdischem Verständnis ist die Zugehörigkeit zur jeweiligen Gemeinschaft der Muslime bzw. Juden eine Frage der Abstammung, die durch eine Entscheidung des Kindes nicht beeinflusst werden kann: Eine jüdische Mutter vermittelt die Zugehörigkeit zum Judentum, ein muslimischer Vater die Zugehörigkeit zum Islam. Besteht die Zugehörigkeit aber schon, so folgt daraus gewissermaßen ein Anspruch des Betroffenen (also des Kindes) entsprechend den (Rechts-)Vorgaben der Gemeinschaft behandelt zu werden. Ein religiöser Jude wird kaum die Notwendigkeit der Beschneidung nach jüdischem Recht bezweifeln, selbst wenn er mit medizinischen oder psychologischen Gegenargumenten konfrontiert wird - nicht etwa, weil er an der Berechtigung solcher Argumente grundsätzlich zweifeln würde, sondern weil diese Argumente für ihn auf einer vergleichsweise geringen statistischen Autorität beruhen, die gegenüber der historischen Autorität rabbinischer Tradition verblasst. Nicht-religiöse Juden - und hier wird ein Problem erkennbar, das mit einem christlichen Religionsverständnis nur bedingt lösbar ist - mögen sich für die Beschneidung ihrer Söhne entscheiden, weil das Judentum mehr ist als eine Glaubensauffassung oder Religion und erst durch christliche Zuschreibungen darauf reduziert wurde.

Stimmt man nun aber dem Ergebnis zu, dass historisch gesehen auch die Beschneidung „zu Deutschland“ gehört, stellt sich die Frage, inwiefern es einen Verstoß gegen § 1 StGB und Art. 103 II GG darstellt, wenn ein Landgericht plötzlich eine Praxis unter Strafe stellt, die dem Gesetzgeber fraglos bekannt war, deren Straflosigkeit aber - wie auch Holm Putzke einräumt - bis 2008 allgemein akzeptiert war. Die Befürworter einer Strafbarkeit der Beschneidung sehen hier offensichtlich kein Problem, dreht sich die die Strafbarkeit begründende Frage doch letztlich „eigentlich“ nur um die Reichweite von § 1627 S. 1 BGB. Tatsächlich aber erfasst das Bestimmtheitsgebot aus Art. 103 II GG und § 1 StGB die Strafandrohung insgesamt (vermittelt durch das Zusammenspiel von Tatbestand, Rechtfertigungs- und Entschuldigungsgründen) - der Gesetzgeber und nicht der Richter ist zur Entscheidung über die Strafbarkeit berufen. Sinn und Zweck des Bestimmtheitsgebotes ist es unstreitig, sicherzustellen, dass die Normadressaten vorhersehen können, welches Verhalten verboten und mit Strafe bedroht ist: Art. 103 II GG fordert also nicht nur die Subsumierbarkeit einer Auslegung unter den Wortlaut der Norm, sondern auch ihre Vorhersehbarkeit. Zwar schützen weder § 1 StGB noch Art. 103 II GG vor inhaltlicher Änderung der Rechtsprechung, insbesondere besteht kein Schutz vor veränderter Auslegung hinreichend bestimmter Begriffe, aber der Grundsatz des Bestimmtheitsgebotes gilt richtiger Auffassung nach auch für Rechtfertigungsgründe - und die Einwilligung ist ein Rechtfertigungsgrund.

Mark Swatek-Evenstein hat über die "Geschichte der 'Humanitären Intervention'" an der Rheinischen FriedrichWilhelms-Universität in Bonn promoviert. Er ist Rechtsanwalt und Fachanwalt für Strafrecht in Berlin.

LICENSED UNDER CC BY NC ND

SUGGESTED CITATION Swatek-Evenstein, Mark: Was, wenn einer der Großväter der Verfassung beschnitten war?, VerfBlog, 2012/8/31, http://verfassungsblog.de/wenn-einer-der-grovter-der-verfassung-beschnitten-war/. 